\title{
The role of risk factors in heart attacks occurring in men with pre-existing ischaemic heart disease
}

\author{
A N PHILlips, A G SHAPER, S J POCOCK, M WALKER, P MACFARLANE \\ From the Department of Clinical Epidemiology and General Practice, Royal Free Hospital School of Medicine, \\ London and *University Department of Medical Cardiology, Royal Infirmary, Glasgow
}

SUMMARY The importance of three risk factors-serum total cholesterol, systolic blood pressure, and cigarette smoking -on the risk of new major ischaemic heart disease events in men who already have evidence of ischaemic heart disease was assessed. Data from the initial examination in a large prospective study of cardiovascular disease in middle aged men (the British Regional Heart Study) were used to separate 7710 men into three groups on the basis of a resting electrocardiogram, a standardised chest pain questionnaire, and recall of a doctor's diagnosis of angina or of a previous heart attack: (group 1) no evidence of ischaemic heart disease (75\%), (group 2) evidence of ischaemic heart disease short of a definite myocardial infarction (20\%), (group 3) definite myocardial infarction (6\%). In the average follow up period of 7.5 years, 443 men suffered a new major event caused by ischaemic heart disease (fatal or non-fatal myocardial infarction or sudden cardiac death). Age standardised event rates were determined for each of the three groups for varying levels of the established risk factors. Cigarette smoking is strongly associated with the event rate in group 1 but in men with existing heart disease, especially group 3, differences in risk between the smoking categories were smaller. The strong relation between systolic blood pressure and event rate persisted in groups 1 and 2 but not in group 3. The positive association between serum concentration of total cholesterol and the event rate was strongest in group 1 and weaker in groups 2 and 3, though it remained highly significant.

These observations, taken together with the results of previous prospective studies and intervention trials, suggest that the important association between serum total cholesterol and the risk of heart attack persists in men with pre-existing ischaemic heart disease, including myocardial infarction. Therefore, in these men the reduction of serum total cholesterol concentration may be at least as important as it is in men without evidence of ischaemic heart disease.

Raised serum concentration of total cholesterol, high blood pressure, and cigarette smoking are well established risk factors for primary events in ischaemic heart disease. In men who have developed ischaemic heart disease, including survivors of acute myocardial infarction, the control of raised blood pressure and advice against smoking are well accepted in management. The importance of control of serum total cholesterol is more controversial and in general is not regarded as important. ${ }^{1}$

Follow up studies of myocardial infarction patients have shown that the most powerful predictors of

Requests for reprints to Dr A N Phillips, Department of Clinical Epidemiology and General Practice, Royal Free Hospital School of Medicine, Rowland Hill Street, London NW3 2PF.

Accepted for publication 16 June 1988 ischaemic heart disease death within the first few months and years after a myocardial infarction are those which reflect the condition of the myocardium and the loss of ventricular function. ${ }^{2}$ The findings of the few studies that have considered the predictive effect of serum concentration of total cholesterol (measured at least one month after the myocardial infarction) have resulted in uncertainty about its relevance in survivors of myocardial infarction..$^{3-7} \mathrm{~A}$ large prospective study of civil servants in London found that the serum concentration of total cholesterol was strongly associated with risk of death from ischaemic heart disease in those with evidence of preexisting ischaemic heart disease. ${ }^{8}$ Systolic blood pressure and cigarette smoking had weaker associations among men with evidence of ischaemic heart disease than in men initially free of the disease. 
Results from a large secondary prevention trial of cholesterol-reducing drugs suggest that they reduce the risk of ischaemic heart disease events. ${ }^{9}$

We present the results of the British Regional Heart Study, a large prospective study of ischaemic heart disease, which provide further evidence on the role of serum concentrations of total cholesterol and other major risk factors in men with evidence of ischaemic heart disease at the initial screening examination.

\section{Patients and methods}

The British Regional Heart Study examined 7735 men aged 40-59 years drawn at random from the age and sex registers of one general practice in each of 24 towns in England, Wales, and Scotland. The criteria for selecting the towns, general practices, and men have been described. ${ }^{1011}$ In brief, the 24 towns were taken from those with populations of $50000-100000$ (1971 census). They covered the full range of mortality from cardiovascular disease and included all major geographic regions. The general practice in each town was required to have a social class distribution representative of that town. There was no attempt to exclude men with cardiovascular problems. The response rate was $78 \%$.

Research nurses administered a questionnaire and examined each man. Details of the measurement of serum concentrations of lipids, blood pressure, smoking behaviour, electrocardiographic abnormalities, the man's recall of a doctor's diagnosis of heart disease, and the administration of a standardised chest pain questionnaire have all been reported. ${ }^{10-15}$ Men were regarded as having angina if they had indicated on the questionnaire that they had chest pain on exertion (walking uphill or hurrying). This included definite and possible angina. ${ }^{11}$

\section{CATEGORIES OF PRE-EXISTING ISCHAEMIC HEART DISEASE}

The men were separated into three groups according to the extent of evidence of ischaemic heart disease present at screening.

Group 1.-Men with no evidence of ischaemic heart disease.

Group 2.-Men with evidence suggesting ischaemic heart disease short of a definite myocardial infarction. This group contains those with electrocardiographic evidence of definite myocardial ischaemia at rest but not definite myocardial infarction, those with angina or a possible myocardial infarction on chest pain questionnaire, or with a doctor's diagnosis of angina.

Group 3.-Men with a previous definite myocardial infarction according to electrocardiographic evidence or who recalled a doctor's diagnosis of a heart attack. About half the men with electrocardiographic evidence of a definite myocardial infarct had no history of chest pain.

\section{FOLLOW UP}

All men examined in 1978-80 are being followed up for cardiovascular morbidity and for mortality from all causes for eight years. ${ }^{12}$ In the present analysis follow up (to December 1986) ranges from six and a half to eight years, with an average of 7.5 years, and follow up has been achieved for $99 \%$ of the original cohort. A new major event caused by ischaemic heart disease (fatal or non-fatal) occurred in 443 men - that is they became cases. A fatal event was considered to have occurred if ischaemic heart disease (ICD codes 410-414) was recorded as the underlying cause of death. Non-fatal myocardial infarction was diagnosed according to World Health Organisation criteria. $^{11}$

\section{STATISTICAL METHODS}

Logistic regression models were fitted in order to standardise for age and other risk factors when we examined the association between a given risk factor and risk of an event caused by ischaemic heart disease. ${ }^{16}$ The $p$ values in figs 2 and 3 correspond to the risk factor fitted in its original continuous form. We tested for interaction between a given risk factor and ischaemic heart disease group by the likelihood ratio test.

\section{Results}

Table 1 shows the number of men and the number of cases in each of the three groups. Approximately $25 \%$ (1943) of the 7710 men for whom ischaemic heart disease group at screening is known had evidence suggesting the presence of ischaemic heart disease. The men in group 2 had about twice the risk of a future event as those in group 1 . Those men who have evidence of a definite previous myocardial infarction (group 3) have more than six times the risk of men in group 1. The mean age increases with increasing strength of evidence of pre-existing

Table 1 Occurrence of new major events caused by ischaemic heart disease in three groups according to evidence of ischaemic heart disease at initial examination (see Methods)

\begin{tabular}{lrcc}
\hline & Group 1 & Group 2 & Group 3 \\
\hline New events & 217 & 122 & 102 \\
No of men & 5767 & 1515 & 428 \\
Event rate (per 1000/yr) & 5.1 & 10.8 & 31.7 \\
Mean age (yr) & 49.8 & 51.1 & 53.3 \\
Age standardised event rate & 5.3 & 10.5 & 28.4 \\
$\quad$ (per 1000/yr) & 5.3 & & \\
\hline
\end{tabular}


Table 2 Risk factor levels in three groups according to evidence of ischaemic heart disease at initial examination

\begin{tabular}{|c|c|c|c|}
\hline & Group 1 & Group 2 & Group 3 \\
\hline $\begin{array}{l}\text { Cigarette smoking: } \\
\text { Never smoked (\%) } \\
\text { Current smokers (\%) }\end{array}$ & $\begin{array}{l}25 \\
35\end{array}$ & $\begin{array}{l}21 \\
44\end{array}$ & $\begin{array}{l}13 \\
46\end{array}$ \\
\hline $\begin{array}{l}\text { Systolic blood pressure: } \\
\text { Mean (mm Hg) } \\
\% \geq 161 \mathrm{~mm} \mathrm{Hg}\end{array}$ & $\begin{array}{r}144.0 \\
18.3\end{array}$ & $\begin{array}{r}148.7 \\
25.0\end{array}$ & $\begin{array}{r}148 \cdot 2 \\
24.3\end{array}$ \\
\hline $\begin{array}{l}\text { Serum total cholesterol: } \\
\text { Mean (mmol/1) } \\
\% \geqslant 7.2 \mathrm{mmol} / 1\end{array}$ & $\begin{array}{c}6.27 \\
18.6\end{array}$ & $\begin{array}{c}6.33 \\
20.6\end{array}$ & $\begin{array}{c}6.57 \\
26.8\end{array}$ \\
\hline
\end{tabular}

ischaemic heart disease. The age standardised rates show that age explains only a small proportion of the differences in crude event rates.

This report concentrates on three major risk factors for ischaemic heart disease: serum concentration of total cholesterol, cigarette smoking, and systolic blood pressure. Table 2 shows the levels of these risk factors for each of the three groups. The percentage of men who have never smoked decreased across the three groups while the percentage who are current smokers increased. For systolic blood pressure the mean valice and the percentage in the top fifth of the overall distribution ( $\geqslant 161 \mathrm{~mm} \mathrm{Hg}$ ) were higher in those with existing ischaemic heart disease (groups 2 and 3). Mean systolic blood pressures were similar in groups 2 and 3 . This could be because blood pressure tends to fall after a myocardial infarction or because of treatment with $\beta$ blockers after myocardial infarction, or both. Mean serum concentrations of total cholesterol and percentages of men with concentrations $\geqslant 7.2 \mathrm{mmol} / 1$ (the top fifth of the overall distribution) increased progressively from group 1 to group 2 and from group 2 to group 3.

Figures 1-3 show the association between the risk factors at screening and the rate of major events caused by ischaemic heart disease in each of the three groups. For each risk factor the event rates are standardised for age alone, because standardisation for the other risk factors made very little difference to the results.

Figure 1 shows event rates for three categories of current cigarette smoking: never smoked cigarettes, ex-cigarette smoker, and current cigarette smoker. For men in group 1 there is a strong association between cigarette smoking state and risk of new events caused by ischaemic heart disease. The men who had never smoked cigarettes had the lowest rate, followed by the ex-cigarette smokers, and then by the current cigarette smokers. As one moves from group 1 through to group 3 the association between smoking state and the rate of events caused by ischaemic heart disease is somewhat reduced, in terms of the relative risk between smoking categories. In group 3 those who had never smoked were at lower risk than men in the other two smoking groups, although not significantly so, but there is little discernible difference in risk between the current smokers and ex-cigarette smokers. This may be because there was a smaller difference in the mean number of years men had smoked between the ex-smokers and current smokers in group 3 (9.5 years) than in the other two groups (13 years).

To examine the association with systolic blood pressure (fig 2) we divided the overall distribution into thirds. For men in groups 1 and 2 there is a strong and highly significant trend for the event rate to increase with systolic blood pressure. Among men with a previous definite myocardial infarction, however, there was no trend in event rates. One possible explanation for this might be that some men with systolic blood pressure in the lower two thirds of the distribution had had high values which were subsequently lowered by treatment, but that the risk level in these men did not fall correspondingly. This explanation seems unlikely, however, because the exclusion of all men who said they were taking antihypertensive drugs (22\% of men in group 3$)$ did not alter the trend.

To examine the association with serum concentrations of total cholesterol (fig 3 ) we again divided the distribution into thirds. In men with no sign of ischaemic heart disease at screening (group 1) there was a strong and highly significant tendency for the event rate to increase with the serum concentration of total cholesterol.

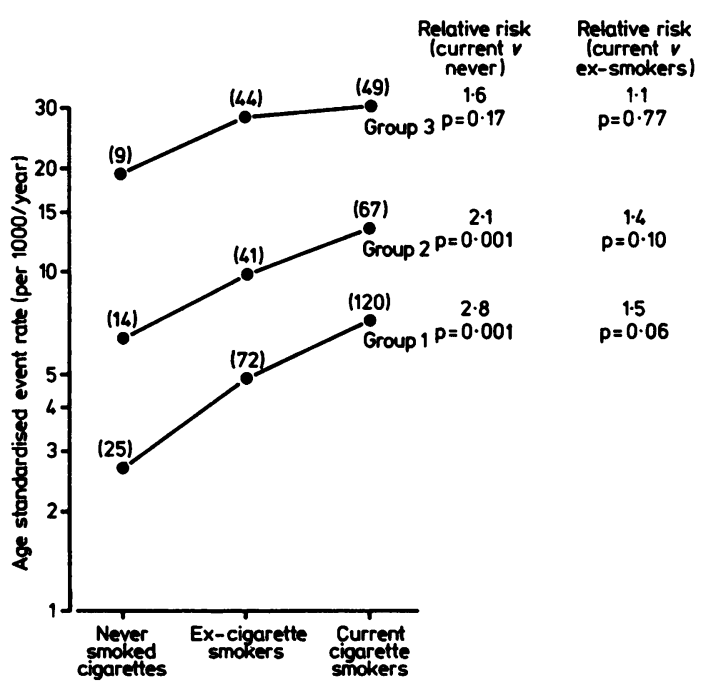

Fig 1 Age standardised event rate by cigarette smoking state for each of three groups classified by evidence of ischaemic heart disease at initial examination. Numbers of cases are given in parentheses. 


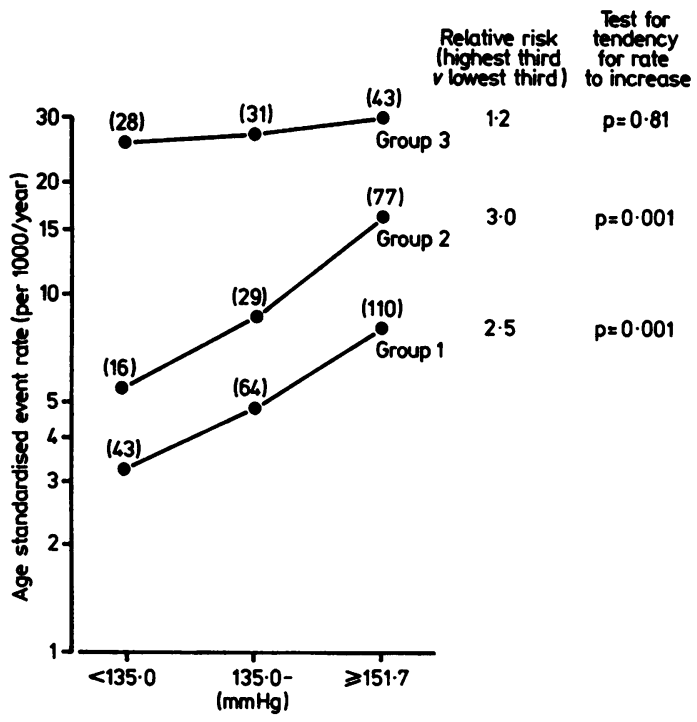

Fig 2 Age standardised event rate according to distribution (thirds) of systolic blood pressure for each of three groups classified by evidence of ischaemic heart disease at initial examination. Numbers of cases are given in parentheses.

This association was slightly reduced in men with existing ischaemic heart disease, but even in men with a previous definite myocardial infarction (group 3) a significant trend persisted $(p=0.01)$.

Antihypertensive drugs (thiazides, propranolol) affect serum concentrations of lipids. ${ }^{11} 18$ When men who said they were taking such drugs were excluded, the trend in group 3 was still apparent. As it was when men taking lipid lowering drugs $(6 \%$ of men in group 3) were excluded.

The three major risk factors were acting simultaneously on the risk of new major events caused by ischaemic heart disease, and it is necessary to use multiple logistic models to determine the independent effect of each risk factor standardised for the effects of the other two risk factors. Table 3 shows the relative risk of a new major event caused by ischaemic heart disease for a specified difference in the level of the risk factor for each group. For each risk factor, the relative risk falls as one moves from group 1 to group 3, the decrease being least for serum total cholesterol, and more pronounced for systolic blood pressure and cigarette smoking. This decrease was statistically significant (in a test for interaction) only for systolic blood pressure $(p<0.05)$. This statistical presentation confirms that standardisation for the other risk factors, in addition to age, makes little difference to the findings presented in figs 1-3. In table 3 only the relative risks in the three ischaemic heart disease groups can be compared for each risk factor; the relative risks within each ischaemic heart disease group-that is, vertical columns-cannot be compared.

\section{Discussion}

These results from the British Regional Heart Study indicate that in men with pre-existing ischaemic heart disease, even in those with a previous myocardial infarction, the serum concentration of total cholesterol remains of prognostic importance. This finding is consistent with that from the Whitehall study of male civil servants in which the association between serum total cholesterol and risk of death from ischaemic heart disease was determined in 2700 men (130 events) with evidence of myocardial ischaemia (according to the electrocardiograph and chest pain questionnaire) and in 14863 men (134 events) with no such evidence. ${ }^{8}$ The association between serum total cholesterol and death from coronary heart disease was found to be as strong in those with evidence of ischaemic heart disease as it was in those without. Separate results were not given for those who had experienced a previous definite myocardial infarction.

Other prospective studies that have measured the prognostic importance of serum total cholesterol in men with a previous myocardial infarction have been based on the follow up of patients with myocardial

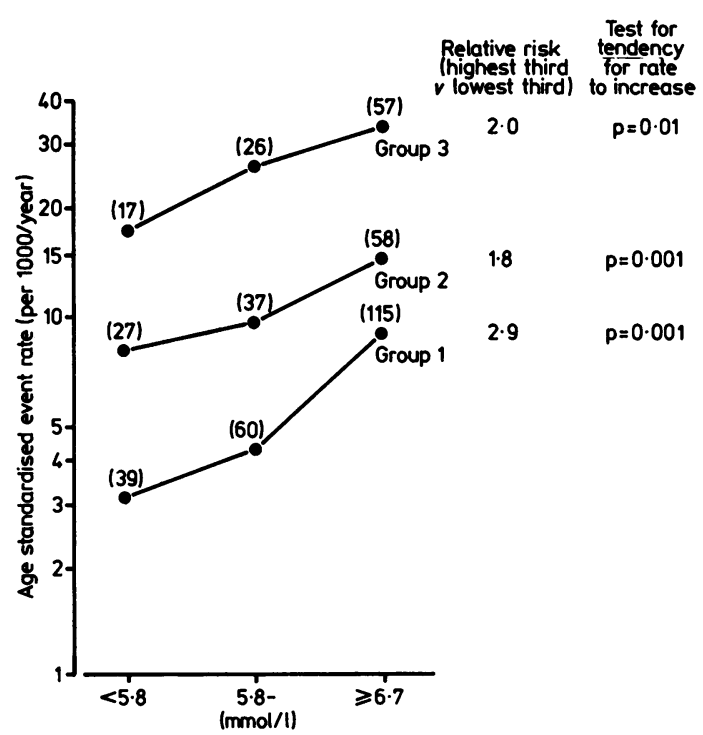

Fig 3 Age standardised event rate according to distribution (thirds) of serum total cholesterol for each of three groups classified by evidence of ischaemic heart disease at initial examination. Numbers of cases are given in parentheses. 
Table 3 Estimates of relative risk standardised for other risk factors in three groups according to evidence of ischaemic heart disease at initial examination

\begin{tabular}{|c|c|c|c|c|}
\hline \multirow[b]{2}{*}{ Risk factor } & \multirow[b]{2}{*}{ Comparison } & \multicolumn{3}{|c|}{ Relative risk } \\
\hline & & $\begin{array}{l}\text { Group } \\
I\end{array}$ & $\begin{array}{l}\text { Group } \\
2\end{array}$ & $\begin{array}{l}\text { Group } \\
3\end{array}$ \\
\hline $\begin{array}{l}\text { Serum total } \\
\text { cholesterol } \\
\text { Systolic blood }\end{array}$ & $\begin{array}{c}1 \mathrm{mmol} / 1 \\
\text { difference } \\
10 \mathrm{~mm} \mathrm{Hg}\end{array}$ & 1.5 & 1.5 & $1 \cdot 3$ \\
\hline $\begin{array}{l}\text { pressure } \\
\text { Cigarette } \\
\text { smoking }\end{array}$ & $\begin{array}{l}\text { difference } \\
\text { Current } v \text { ex } \\
\text { Current } v \text { never }\end{array}$ & $\begin{array}{l}1.2 \\
1.4 \\
2.9\end{array}$ & $\begin{array}{l}1.2 \\
1.5 \\
2 \cdot 1\end{array}$ & $\begin{array}{l}1.0 \\
1.1 \\
1.9\end{array}$ \\
\hline
\end{tabular}

infarction, rather than being of a general population, as in the British Regional Heart Study. When studies with different sampling approaches concur this gives additional support to their findings. Table 4 summarises the studies. ${ }^{3-7}$ The range of intervals from the index myocardial infarction to screening was wide. The few small studies in which cholesterol was measured within one month of the index myocardial infarction were not included because lipid concentrations are unstable in the first few weeks after myocardial infarction. ${ }^{19}$ In the British Regional Heart Study the time since the previous myocardial infarction is unknown, but is likely to be several years.

By far the largest study in terms of the numbers of events, which is the factor of critical importance, ${ }^{20}$ is the control group from the United States Coronary Drug Project. ${ }^{6}$ The risk in those in the highest fifth of the distribution of serum total cholesterol was $\mathbf{5 0 \%}$ higher than that in the lowest fifth $(p=0.001)$. Results from the next three largest studies-Gothenburg, ${ }^{5}$ the Aspirin Myocardial Infarction Study, ${ }^{7}$ and the present study-generally accord with this finding. The relative risk in the British Regional Heart Study was higher, perhaps because some of the index myocardial infarctions (32\%) were silent and presumably less severe. The two smallest studies, the New York Health Insurance Plan Study ${ }^{3}$ and the Toronto study, ${ }^{4}$ did not show that the relative risk increased with serum total cholesterol; however, the findings were not statistically significant. The results of these prospective studies accord with the findings from the Coronary Drug Project trial of the effect of cholesterol-lowering drugs on patients with myocardial infarction, by far the largest trial of cholesterollowering regimens among such subjects.' Results showed a significantly lower rate of events caused by ischaemic heart disease in those on cholesterollowering drugs than in controls. Other trials of cholesterol-lowering drugs or diets in survivors of myocardial infarction are much smaller but have tended to show a lower rate for events caused by ischaemic heart disease in the group on active treatment. ${ }^{21}$ An overview of all randomised trials ${ }^{22}$ of regimens for reducing cholesterol, primary or secondary, has shown that they significantly $(p<0.00001)$ reduce the rate of events caused by ischaemic heart disease.

It seems that in men who have suffered a previous myocardial infarction serum concentrations of total cholesterol continue to be associated with risk of major events caused by ischaemic heart disease. In terms of relative risk, the strength of this association is smaller among these men than it is among those who have no signs of ischaemic heart disease (relative risks between high and low thirds of 2.9 and 2.0 for groups 1 and 3 respectively (fig 3 ). However, the difference (as opposed to the ratio) in risk rate between those with high and those with low serum concentrations of total cholesterol is greater in men with a previous myocardial infarction than in men with no signs of ischaemic heart disease. The difference in event rates between high and low thirds of the distribution of serum cholesterol is $18.4 \%$ $(35 \cdot 3-16.9 \%)$ for group 3 and $5 \cdot 7 \%(8 \cdot 8-3 \cdot 1 \%)$ for group 1 (fig 3). Thus the attributable risk for total cholesterol is higher in men with a previous myocardial infarction because of the very high absolute values for risk. These findings suggest that the potential benefit of a policy of reducing cholesterol, in terms of the number of events postponed or prevented for a given number of men covered, is larger in men with a previous myocardial infarction than it is in men with no evidence of ischaemic heart

Table 4 Summary of results from prospective studies on the prognostic importance of serum total cholesterol in men with a previous myocardial infarction (MI)

\begin{tabular}{|c|c|c|c|c|}
\hline Study & $\begin{array}{l}\text { Average time from index } M I \\
\text { to screening }\end{array}$ & $\begin{array}{l}\text { Number and type of new } \\
\text { events }\end{array}$ & $\begin{array}{l}\text { Estimated relative risk of } \\
\text { new event }\end{array}$ & p value \\
\hline $\begin{array}{l}\text { Coronary Drug Project (1978) } \\
\text { Gothenburg (1984) } \\
\text { AMIS (1987) } \\
\text { BRHS }(1987) \\
\text { HIP }(1970)^{3} \\
\text { Toronto }(1970)^{4}\end{array}$ & $\begin{aligned} & 3 \text { years } \\
& 3 \text { months } \\
\simeq & 3 \text { years } \\
& 6 \text { months } \\
& 3 \text { years }\end{aligned}$ & $\begin{array}{l}748 \text { (MI) } \\
254 \text { (death_any cause) } \\
343 \text { (CVD death) } \\
100 \text { (MI) } \\
79 \text { (MI) } \\
55 \text { (MI) }\end{array}$ & $\begin{array}{l}1.5 \\
1.4 \\
1.3 \\
2.0 \dagger \\
0.6^{\star} \\
1.0^{\star}\end{array}$ & $\begin{aligned} & 0.001 \\
& 0.02 \\
&<0.1 \\
& 0.01 \\
&>0.1 \\
&>0.5\end{aligned}$ \\
\hline
\end{tabular}

Relative risk compares extreme fifths, *halves, or thirds.

AMIS, Aspirin Myocardial Infarction Study; BRHS, British Regional Heart Study; HIP, Health Insurance Plan Study; CVD, cardiovascular disease. 
disease.

In the Whitehall study, the relative risk of mortality from ischaemic heart disease in men who were cigarette smokers at screening compared with those who were not was less in men with evidence of preexisting ischaemia than in those without. ${ }^{8}$ Similarly, in the control group of the Coronary Drug Project trial there was only a small (but statistically significant) difference in risk of coronary death or myocardial infarction between smokers and nonsmokers. ${ }^{23}$ These two sets of findings are consistent with our own. However, in neither the Whitehall nor the Coronary Drug Project reports were non-smokers divided into ex-smokers and those who had never smoked. This is unfortunate because results in the present report suggest that ex-smokers with a previous myocardial infarction experience a level of risk closer to that of current smokers than to that of those who have never smoked.

In the Whitehall Study, systolic blood pressure retained a moderately strong association with the risk of death from coronary heart disease in men with signs of ischaemia. ${ }^{8}$ In the control group of the Coronary Drug Project trial, only a very small (nonsignificant) association between systolic blood pressure and risk of future coronary death or non-fatal myocardial infarction was found. ${ }^{2}$ Once again, these results are consistent with our own. The reasons for the apparent lack of an association in men who have had a previous myocardial infarction are uncertain and do not appear to be explained by treatment. One explanation is that those men with the most severe impairment of left ventricular function by the myocardial infarction will tend to have lower blood pressure but higher risk of future events than other men. ${ }^{24}$

These findings from the British Regional Heart Study indicate that serum total cholesterol, a powerful risk factor for initial major events caused by ischaemic heart disease, influences the risk of such events in men with evidence of ischaemic heart disease, including those with definite previous myocardial infarction. This observation is supported by other prospective studies and by trials of regimens that reduce the serum concentration of total cholesterol in men with previous myocardial infarction. We conclude that reduction of serum concentrations of total cholesterol in men with any evidence of ischaemic heart disease is at least as important as it is in men without evidence of ischaemic heart disease.

The British Regional Heart Study is a British Heart Foundation Research group and is also supported by the Medical Research Council, Department of Health and Social Security, and the Chest, Heart and Stroke Association. Serum total cholesterol was measured in the Wolfson Research Laboratories (Professor T P Whitehead) supported by the Department of Health and Social Security. Computerised electrocardiography (PWM) was supported by the Scottish Home and Health Department and the Greater Glasgow Health Board.

\section{References}

1 Oliver MF. Why measure cholesterol after myocardial infarction and when? $\mathrm{Br}$ Med J 1984;289:1641-2.

2 Schlant RC, Forman S, Stamler J, Canner P. The natural history of coronary heart disease: prognostic factors after recovery from myocardial infarction in 2789 men. The five-year findings of the Coronary Drug Project. Circulation 1982;66:401-4.

3 Frank CW, Weinblatt E, Shapiro S. Prognostic implications of serum cholesterol in coronary heart disease. In: Jones RJ, ed. Atherosclerosis. Proceedings of the second international symposium. Berlin: Springer Verlag, 1970:390-9.

4 Shanoff HM, Little JA, Csima A. Studies of male survivors of myocardial infarction: XII. Relation of serum lipids and lipoproteins to survival over a 10 year period. Can Med Assoc J 1970;103:927-31.

5 Ulvenstam G, Bergstrand R, Johansson S, et al. Prognostic importance of cholesterol levels after myocardial infarction. Prev Med 1984;13:355-66.

6 Coronary Drug Project Research Group. Natural history of myocardial infarction in the Coronary Drug Project: long-term prognostic importance of serum lipid levels. Am J Cardiol 1978;41:489-98.

7 Frost PH, Verter J, Miller D. Serum lipids and lipoproteins after myocardial infarction: associations with cardiovascular mortality and experience in the Aspirin Myocardial Infarction Study. Am Heart J 1987;113:1356-64.

8 Rose G, Reid DD, Hamilton PJS, McCartney P, Keen $H$, Jarrett RJ. Myocardial ischaemia, risk factors and death from coronary heart-disease. Lancet 1977; 105-9.

9 Coronary Drug Project Research Group. Clofibrate and niacin in coronary heart disease. JAMA 1975;231: 360-81.

10 Shaper AG, Pocock SJ, Walker M, Cohen NM, Wale CJ, Thomson AG. British Regional Heart Study: cardiovascular risk factors in middle-aged men in 24 towns. Br Med J 1981;283:179-86.

11 Shaper AG, Pocock SJ, Walker M, Phillips AN, Whitehead TP, Macfarlane PW. Risk factors for ischaemic heart disease: the prospective phase of the British Regional Heart Study. J Epidemiol Community Health 1985;39:197-209.

12 Walker M, Shaper AG. Follow-up of subjects in prospective studies based in general practice. $J \boldsymbol{R}$ Coll Gen Pract 1984;34:365-70.

13 Shaper AG, Cook DG, Walker M, Macfarlane PW. Prevalence of ischaemic heart disease in middle aged British men. Br Heart J 1984;51:595-605. 
14 Shaper AG, Cook DG, Walker M, Macfarlane PW. Recall of diagnosis by men with ischaemic heart disease. Br Heart J 1984;51:606-11.

15 Thelle DS, Shaper AG, Whitehead TP, Bullock DG, Ashby D, Patel I. Blood lipids in middle-aged British men. Br Heart J 1983;49:205-13.

16 Walker SH, Duncan DB. Estimation of the probability of an event as a function of several independent variables. Biometrika 1967;54:167-79.

17 Grimm RH, Leon AS, Hunningshake DB, Lenz K, Hannan P, Blackburn H. Effects of thiazide diuretics on plasma lipids and lipoproteins in mildly hypertensive patients. Ann Intern Med 1981;94:7-11.

18 Miall WE, Greenberg G. Mild hypertension: is there pressure to treat? Cambridge: Cambridge University Press, 1987:146-8.

19 Ryder REJ, Hayes TM, Mulligan IP, Kingswood JC,
Williams S, Owens DR. How soon after myocardial infarction should plasma lipid values be assessed? $\mathrm{Br}$ Med J 1984;289:1651-3.

20 Schlesselmann JJ. Sample size requirements in cohort and case-control studies of disease. Am J Epidemiol 1974;32:415-25.

21 Sleight P, Jones JV, eds. Scientific foundations: cardiology. London: Heinemann, 1983:284-9.

22 Peto R, Yusuf S, Collins R. Cholesterol-lowering trial results in their epidemiological context [Abstract]. Circulation 1985;72(suppl III):451.

23 Coronary Drug Project Research Group. Cigarette smoking as a risk factor in men with a prior history of myocardial infarction. J Chronic Dis 1979;32:415-25.

24 Kannel WB, Sorlie P, Castelli WP, McGee D. Blood pressure and survival after myocardial infarction: the Framingham Study. Am J Cardiol 1980;45:326-30. 